\title{
Analysis of Difference in Importance and Need for Basic Core Competence of Clinical Dental Hygienists
}

\author{
Sun-Mi Lee, Chun-Sun Lee, and Myong-Suk Shin ${ }^{\dagger}$ \\ Department of Dental Hygiene, Dongnam Health University, Suwon 16328, Korea
}

\begin{abstract}
Background: The objective of this study is to investigate the needs and importance of basic core competencies required for future society by dental hygienists' viewpoints who are working in the clinical practices and to provide the fundamental data to develop the educational programs based on the competencies in the 21st century so as to enhance their working capability.

Methods: A total of 38 questionnaires were used in this study, 3 questionnaires on the general characteristics (age, service years, main job functions) and those in 11 sub-factors of basic core competencies including 4 questionnaires on creativity, 3 on collaboration, 3 on communication, 3 on interpersonal relationship, 3 on problem-solving, 4 on resource control, 4 on selfcontrol and development, 2 on vocational ethics, 3 on knowledge information utilization, 3 on global mind, and 3 on emotional intelligence. Self-reported survey was conducted in the dental hygienists who were working in Seoul and Gyeonggi Province and a total of 195 data were analyzed.

Results: Vocational ethics, communication, and collaboration showed the highest on both importance and needs with 4.49 points and 4.34; 4.41 and 4.28; and 4.39 and 4.22, respectively, while global mind showed the lowest with 3.51 and 3.59. Upon Importance-Performance Analysis, 7 items were defined to require maintain the status including vocational ethics, communication, collaboration, interpersonal relationship, self-control, emotional intelligence, and problem-solving while 4 items with lower priority were resource control and development, knowledge information utilization, creativity, and global mind.

Conclusion: Based on this study results that suggested the basic core competencies of dental hygienists in alignment with their jobs in the future society, competitive dental hygienists should be developed with the educational programs applied with these competencies.
\end{abstract}

Key Words: Basic core competencies, Dental hygienists, Importance-performance analysis

\section{Introduction}

Interest level in the health of medical consumers has been increasing in Korea due to aging population, improvement of quality of life, and so on, thus, consumers' right has been improved and medical services have been advanced and diversified. In the dental service field, hygienists' job scope has been expanded to be more professional and independent beyond the traditional roles, in providing multiple services for the enhancement of public dental health. As such, the importance of core competencies has been paid attention more as the essential and common capabilities of life according to the rapid change of the society ${ }^{1)}$.

University courses should include the education of the basic capabilities based on core competencies by basic liberal arts subjects as well as major ones, moreover, support the students to acquire the required capabilities in their prospective jobs by themselves ${ }^{2)}$. Hence, it is necessary to review whether the university education is met to the expected roles from the nation and the society. The minimum function of university education should be considered that students will be able to play the expected roles in the society after graduation ${ }^{3)}$. 
Core competencies, as integrated knowledge, skills, and attitude required for the learners to solve a variety of problems or phenomena efficiently, are basic and common capabilities to be developed by the university education rather than personally owned talents ${ }^{4)}$. Core competencies mean the main skills that individuals possess to perform learning, job-seeking, working, and so on, which can be changed by learning and they are not inborn and unchangeable capabilities ${ }^{5)}$. New dental hygienists should realize the role model in the hospital environment, have the core competencies required for the long-term growth of the hospitals, and have the capability to demonstrate those competencies before long. However, new workers do not reach the required level in the clinical practices due to lack of professional understanding and skillsets, so it is necessary for the students majoring in dental hygiene to develop core competencies systemically to be able to cope with the problems proactively in the clinical practices after their graduation.

Although a few studies have been conducted on the core competencies in the general university students ${ }^{1,6,7)}$, the competence of dental hygienists has also been developed, but research on the core competencies based on the talent required by the industry in relation to the job of dental hygienists is insufficient. Hence, through the opinions of dental hygienists currently working in clinical practice, we intend to grasp the basic and common skills required to effectively perform the job of dental hygiene. Fundamental data for developing a curriculum program so that dental hygienists can improve their job skills in the dental medical environment in the era of the 4th industrial revolution by deriving the basic core competency required for the dental hygienist's job, and that these basic core competencies can be linked with major subjects.

\section{Materials and Methods}

\section{Subjects}

The subjects were 250 dental hygienists selected by random sampling among the licensed dental hygienists working in Seoul and Gyeonggi Province. Self-reported survey was conducted. Sample size was calculated using $\mathrm{G}^{*}$ Power 3.1.9.2 with significance level 0.05, median effect size 0.30 , and the test power 0.95 , to be applied with the calculated outcome 176 persons. 195 copies were used for the final analysis excluding 55 copies with inappropriate answers among the collected data.

\section{Methods}

The tool developed by Kwon et al. ${ }^{8)}$ was modified to meet the objective of this study. Self-reported survey was conducted with a total of 38 questionnaires including 3 questionnaires on general characteristics (age, service years, and main job functions) and 11 sub-factors of basic core competencies including 4 questionnaires on creativity (competency to generate new, valuable and useful ideas or outcomes by interactions between creative thinking and attitudes); 3 on collaboration (competency to be able to maintain effective collaborative relationship with others upon active communication with considerate, respectful, and ethical attitudes); 3 on communication (competency to be able to deliver his/her own opinion and information effectively upon understanding the meanings of other's letters and words and responding appropriately); 3 on interpersonal relationship (competency to be able to understand a variety of opinions and positions of other members, develop the relationship with members positively, and control the conflicts harmoniously); 3 on problemsolving (competency to be able to recognize the causes of the problems and solve the problems with proper alternatives by creative and logical thinking based on the objective data in case problems are occurred in the job); 4 on resource control (competency to be able to check what and how much are required among time, financial, physical, and human resources for job performances, plan how to use the resources upon collecting them as many as possible, and allocate them in his/her job as planned); 4 on self-control and development (competency to be able to establish proper career development plan based the understanding of his/her own career path, develop and manage the basic skills and capabilities required for his/her life and career, and adapt the changing society flexibly); 2 on vocational ethics (competency to be able to understand and practice internal and external behavioral standards in the socially expected attitudes, manners, proper view on the job, and so on when performing the job 
within the organization as the rules that all the members should follow commonly in the organization.); 3 on knowledge information utilization (competency to be able to collect, analyze, and utilize the information from a variety of fields for searching logical problem-solving methods, executions and evaluation of these methods, media utilization, and so on in the workplace); 3 on global mind (competency to be able to accept the global trends, develop international insights, cope with cultural diversity and global environment flexible, and express himself/ herself in good foreign languages); and 3 on emotional intelligence (competency to be able to understand the others' feeling accurately and control his/her own feeling well for harmonious life in the organization and job performances).

With respect to the reliability of the tool, Cronbach's $\alpha$ of creativity, collaboration, communication, interpersonal relationship, problem-solving, resource control, self-control and development, vocational ethics, knowledge information utilization, global mind, and emotional intelligence were $0.816,0.930,0.891,0.874,0.900,0.918,0.913,0.881$, $0.859,0.867$, and 0.940 , respectively.

\section{Statistical analysis}

Statistical analysis with collected data was performed using PASW Statistics ver. 23.0 (IBM Corp., Armonk, NY, USA). General characteristics on the study data were shown with frequency and percentage. Mean and standard deviation were calculated for the importance and needs by area on the basic core competencies. Paired sample t-test was performed to analyze the difference between importance and needs. In addition, Importance-Performance Analysis (IPA) was performed to compare and analyze the relative importance and satisfaction level of each attribute, simultaneously. Significance level for determination was 0.05 .

\section{Results}

\section{General characteristics}

General characteristics of the study subjects are shown in Table 1 . With respect to age, 20s were the most with $48.7 \%$ followed by 30 s, 40 s and 50 s and older with $30.3 \%$,
$17.4 \%$, and 3.6\%, respectively. For service years, less than 5 years was the most with $51.3 \%$ followed by 10 to 20 years with $22.6 \%, 5$ to 10 years with $20.5 \%$, and over 20 years with $5.6 \%$. Regarding main job functions, 'support clinical dentistry' was $44.1 \%$ followed by 'preventive measures for dental diseases,' 'patient management,' and 'hospital management' with $21.5 \%, 16.9 \%$, and $8.7 \%$, respectively.

\section{Analysis of importance and needs by area on the basic core competencies}

Table 2 show the analysis results of importance and needs by area of basic core competencies.

For creativity, the highest levels of importance and needs were 'creative attitude' with 3.93 points and 'creative problem-solving' with 3.83 points, while the lowest levels of importance and needs were 'diverging thinking' with 3.49 and 3.54 points, respectively. The greatest difference item between importance and needs was 'creative attitude' $(0.11)$, and all the items did not show any significant differences.

For collaboration, 'collaborative communication' showed the highest importance and needs with 4.46 and 4.26 points, respectively, and 'teamwork' showed the lowest with 4.36 and 4.20 points, respectively. 'Collaborative communication' (0.20) showed the greatest difference

Table 1. General Characteristics

\begin{tabular}{llc}
\hline \multicolumn{1}{c}{ Item } & \multicolumn{1}{c}{ Classification } & $\mathrm{n}(\%)$ \\
\hline Age $(\mathrm{y})$ & $20 \mathrm{~s}$ & $95(48.7)$ \\
& $30 \mathrm{~s}$ & $59(30.3)$ \\
& $40 \mathrm{~s}$ & $34(17.4)$ \\
& $50 \mathrm{~s}$ and older & $7(3.6)$ \\
Service years & Less than 5 & $100(51.3)$ \\
& $5 \sim 10$ & $40(20.5)$ \\
& $10 \sim 20$ & $44(22.6)$ \\
& Over 20 & $11(5.6)$ \\
Main job functions & Support clinical dentistry & $86(44.1)$ \\
& Preventive measures for & $42(21.5)$ \\
& dental diseases & $3(1.5)$ \\
& Dental health education & $33(16.9)$ \\
& Patient management & $17(8.7)$ \\
& Hospital management & $6(3.1)$ \\
Total & Coordinator & $8(4.1)$ \\
& Other & $195(100.0)$ \\
\hline & & \\
& &
\end{tabular}


Table 2. Importance and Needs by Basic Core Competencies

\begin{tabular}{|c|c|c|c|c|}
\hline \multirow{2}{*}{ Item } & \multirow{2}{*}{$\begin{array}{c}\text { Importance } \\
\text { Mean } \pm \text { standard deviation }\end{array}$} & \multirow{2}{*}{$\begin{array}{c}\text { Needs } \\
\text { Mean } \pm \text { standard deviation }\end{array}$} & \multicolumn{2}{|c|}{ Importance - needs } \\
\hline & & & Mean difference & $t\left(p^{a}\right)$ \\
\hline \multicolumn{5}{|l|}{ Creativity } \\
\hline Diverging thinking & $3.49 \pm 1.00$ & $3.54 \pm 1.03$ & -0.05 & $-0.839(0.403)$ \\
\hline Converging thinking & $3.87 \pm 0.93$ & $3.82 \pm 0.94$ & 0.04 & $0.904(0.367)$ \\
\hline Creative attitude & $3.93 \pm 0.96$ & $3.82 \pm 1.00$ & 0.11 & $1.819(0.070)$ \\
\hline Creative problem-solving & $3.89 \pm 0.95$ & $3.83 \pm 1.01$ & 0.05 & $0.940(0.349)$ \\
\hline Total & $3.79 \pm 0.77$ & $3.75 \pm 0.82$ & 0.04 & $0.921(0.358)$ \\
\hline \multicolumn{5}{|l|}{ Collaboration } \\
\hline Teamwork & $4.36 \pm 0.85$ & $4.20 \pm 0.91$ & 0.16 & $3.427(0.001)$ \\
\hline Collaborative communication & $4.46 \pm 0.80$ & $4.26 \pm 0.85$ & 0.20 & $3.906(<0.001)$ \\
\hline Organization understanding & $4.37 \pm 0.87$ & $4.22 \pm 0.91$ & 0.15 & $3.002(0.003)$ \\
\hline Total & $4.39 \pm 0.78$ & $4.22 \pm 0.84$ & 0.17 & $3.877(<0.001)$ \\
\hline \multicolumn{5}{|l|}{ Communication } \\
\hline Listening & $4.48 \pm 0.76$ & $4.34 \pm 0.76$ & 0.14 & $2.978(0.003)$ \\
\hline Sympathy & $4.40 \pm 0.82$ & $4.25 \pm 0.86$ & 0.15 & $3.096(0.002)$ \\
\hline Expression of opinion & $4.38 \pm 0.84$ & $4.30 \pm 0.87$ & 0.08 & $1.676(0.095)$ \\
\hline Total & $4.41 \pm 0.75$ & $4.28 \pm 0.77$ & 0.12 & $2.950(0.004)$ \\
\hline \multicolumn{5}{|l|}{ Interpersonal relationship } \\
\hline Conflict management & $4.32 \pm 0.88$ & $4.15 \pm 0.88$ & 0.16 & $3.180(0.002)$ \\
\hline Leadership & $4.13 \pm 0.92$ & $4.05 \pm 0.91$ & 0.08 & $1.813(0.071)$ \\
\hline Consideration & $4.28 \pm 0.88$ & $4.11 \pm 0.93$ & 0.16 & $3.648(<0.001)$ \\
\hline Total & $4.24 \pm 0.80$ & $4.10 \pm 0.82$ & 0.14 & $3.452(0.001)$ \\
\hline \multicolumn{5}{|l|}{ Problem-solving } \\
\hline Problem recognition & $3.94 \pm 0.94$ & $3.89 \pm 0.92$ & 0.05 & $1.010(0.314)$ \\
\hline Alternative thinking & $3.99 \pm 0.92$ & $3.97 \pm 0.91$ & 0.02 & $0.458(0.648)$ \\
\hline Problem-handling skill & $4.13 \pm 0.89$ & $4.11 \pm 0.86$ & 0.01 & $0.310(0.757)$ \\
\hline Total & $4.02 \pm 0.84$ & $3.99 \pm 0.83$ & 0.02 & $0.717(0.474)$ \\
\hline \multicolumn{5}{|l|}{ Resource control } \\
\hline Human resource control & $3.85 \pm 1.00$ & $3.70 \pm 1.03$ & 0.14 & $2.701(0.008)$ \\
\hline Physical resource control & $3.92 \pm 0.97$ & $3.81 \pm 0.99$ & 0.11 & $2.269(0.024)$ \\
\hline Financial resource control & $3.82 \pm 0.98$ & $3.68 \pm 1.01$ & 0.13 & $2.513(0.013)$ \\
\hline Time management & $4.03 \pm 0.97$ & $3.88 \pm 1.00$ & 0.14 & $2.881(0.004)$ \\
\hline Total & $3.90 \pm 0.88$ & $3.76 \pm 0.90$ & 0.13 & $3.169(0.002)$ \\
\hline \multicolumn{5}{|l|}{ Self-control and development } \\
\hline Self-recognition & $4.18 \pm 0.90$ & $4.06 \pm 0.92$ & 0.12 & $2.603(0.010)$ \\
\hline Self-assessment & $4.17 \pm 0.87$ & $4.09 \pm 0.87$ & 0.07 & $1.513(0.132)$ \\
\hline Self-development & $4.14 \pm 0.88$ & $4.09 \pm 0.91$ & 0.05 & $1.118(0.265)$ \\
\hline Health control & $4.13 \pm 0.91$ & $3.94 \pm 0.99$ & 0.19 & $3.604(<0.001)$ \\
\hline Total & $4.15 \pm 0.79$ & $4.04 \pm 0.80$ & 0.11 & $2.739(0.007)$ \\
\hline \multicolumn{5}{|l|}{ Vocational ethics } \\
\hline Sense of responsibility & $4.52 \pm 0.86$ & $4.37 \pm 0.90$ & 0.14 & $2.688(0.008)$ \\
\hline Ethical mind & $4.47 \pm 0.78$ & $4.32 \pm 0.89$ & 0.14 & $3.004(0.003)$ \\
\hline Total & $4.49 \pm 0.78$ & $4.34 \pm 0.85$ & 0.14 & $3.138(0.002)$ \\
\hline \multicolumn{5}{|l|}{ Knowledge information utilization } \\
\hline Digital literacy & $3.75 \pm 0.99$ & $3.78 \pm 1.00$ & -0.03 & $-0.611(0.542)$ \\
\hline Technical skill & $4.02 \pm 0.89$ & $3.98 \pm 0.93$ & 0.03 & $0.611(0.542)$ \\
\hline Math skill & $3.63 \pm 0.97$ & $3.62 \pm 0.99$ & 0.01 & $0.204(0.839)$ \\
\hline Total & $3.79 \pm 0.84$ & $3.79 \pm 0.86$ & 0.00 & $0.083(0.934)$ \\
\hline
\end{tabular}


Table 2. Continued

\begin{tabular}{|c|c|c|c|c|}
\hline \multirow{2}{*}{ Item } & \multirow{2}{*}{$\begin{array}{c}\text { Importance } \\
\text { Mean } \pm \text { standard deviation }\end{array}$} & \multirow{2}{*}{$\begin{array}{c}\text { Needs } \\
\text { Mean } \pm \text { standard deviation }\end{array}$} & \multicolumn{2}{|c|}{ Importance - needs } \\
\hline & & & Mean difference & $t\left(p^{a}\right)$ \\
\hline \multicolumn{5}{|l|}{ Global mind } \\
\hline Global mind & $3.46 \pm 1.04$ & $3.52 \pm 1.03$ & -0.06 & $-1.247(0.214)$ \\
\hline Sympathy on multi-culture & $3.42 \pm 1.08$ & $3.47 \pm 1.02$ & -0.05 & $-0.990(0.323)$ \\
\hline Foreign language utilization & $3.67 \pm 1.03$ & $3.79 \pm 0.99$ & -0.12 & $-2.194(0.029)$ \\
\hline Total & $3.51 \pm 0.93$ & $3.59 \pm 0.90$ & -0.08 & $-1.770(0.078)$ \\
\hline \multicolumn{5}{|l|}{ Emotional intelligence } \\
\hline Understanding of emotion & $4.10 \pm 0.95$ & $4.03 \pm 0.91$ & 0.07 & $1.561(0.120)$ \\
\hline Emotion control & $4.19 \pm 0.89$ & $4.08 \pm 0.91$ & 0.10 & $2.303(0.022)$ \\
\hline Emotion using & $4.14 \pm 0.89$ & $3.99 \pm 0.96$ & 0.14 & $2.881(0.004)$ \\
\hline Total & $4.14 \pm 0.86$ & $4.03 \pm 0.88$ & 0.10 & $2.475(0.014)$ \\
\hline
\end{tabular}

The highest score is 5 in a five-point likert scale.

a p-value by t-test.

between importance and needs, and all the items showed the significant differences.

For communication, 'listening' showed the highest importance and needs with 4.48 and 4.34 points, and 'expression of opinion' and 'sympathy' showed the lowest importance and needs with 4.38 and 4.25 points, respectively. 'Sympathy' (0.15) showed the greatest difference between importance and needs, and 'listening' and 'sympathy' showed the significant differences.

For interpersonal relationship, 'conflict management' showed the highest importance and needs with 4.32 and 4.15 points, and 'leadership' showed the lowest importance and needs with 4.13 and 4.05 points, respectively. 'Conflict management' and 'consideration' (0.16) showed the greatest difference between importance and needs, and 'conflict management' and 'consideration' showed the significant differences.

For problem-solving, 'problem-handling skill' showed the highest importance and needs with 4.13 and 4.11 points, and 'problem recognition' showed the lowest importance and needs with 3.94 and 3.89 points, respectively. 'Problem recognition' (0.05) showed the greatest difference between importance and needs, and all the items did not show any significant differences.

For resource control, 'time management' showed the highest importance and needs with 4.03 and 3.88 points, and 'financial resource control' showed the lowest in importance and needs with 3.82 and 3.68 points, respectively. 'Human resource control' and 'time management'
(0.14) showed the greatest difference between importance and needs, and all the items showed significant differences.

For self-control and development, 'self-recognition' showed the highest importance with 4.18 points and 'self-assessment' and 'self-development' showed the highest needs with 4.09 points, while 'health control' showed the lowest importance and needs with 4.13 and 3.94 points, respectively. 'Health control' (0.19) showed the greatest difference between importance and needs, and 'selfrecognition' and 'health control' showed significant differences.

With respect to the vocational ethics, 'sense of responsibility' showed the highest importance and needs with 4.52 and 4.37 points, respectively, and 'ethical mind' showed the importance and needs with 4.47 and 4.32 points, respectively. All the items showed significant differences.

With respect to knowledge information utilization, 'technical skill' showed the highest importance and needs with 4,02 and 3.98 points, respectively, and 'math skill' showed the lowest importance and needs with 3.63 and 3.62 points, respectively. 'Technical skill' (0.03) showed the greatest difference between importance and needs, and all the items did not show any significant differences.

With respect to global mind, 'foreign language utilization' showed the highest importance and needs with 3.67 and 3.79 points, respectively, and 'sympathy on multi-culture' showed the lowest importance and needs with 3.42 and 3.47 points, respectively. 'Foreign language 
utilization' $(-0.12)$ showed the greatest difference between importance and needs, and only 'foreign language utilization' showed significant difference.

With respect to emotional intelligence, 'emotion control' showed the highest importance and needs with 4.19 and 4.08 points, respectively, while 'understanding of emotion' and 'emotion using' showed the low levels of importance and needs with 4.10 and 3.99 points, respectively. 'Emotion using' (0.14) showed the greatest difference between importance and needs, and 'emotion control' and 'emotion using' showed significant differences.

Among the total competencies, the importance showed high in the orders of 'vocational ethics,' 'communication,' 'collaboration,' 'interpersonal relationship,' and 'self-control and development' with 4.49, 4.41, 4.39, 4.24, and 4.15 points, respectively; and the needs showed high in the same orders with $4.34,4.28,4.22,4.10$, and 4.04 points. Competency with the lowest importance and needs was 'global mind' with 3.51 and 3.59 points, respectively, followed by 'creativity' with 3.79 and 3.75 points; and 'knowledge information utilization' with 3.79 and 3.79 points.

\section{Difference analysis of importance and needs using IPA matrix}

IPA provides with the priority information to be improved for the enhancement of basic core competencies of dental hygienists and it is helpful to seek the items for basic core competencies since it displays the detailed items visually from the areas to be required for intensive efforts up to the over-implemented areas ${ }^{9}$.

IPA provides with four quadrant decision makings based on the comparisons with the attributes of importance and needs. Importance and needs are shown in the quadrant matrix as follows (Fig. 1).

11 competencies were analyzed by IPA and the results are shown in Fig. 2. 7 items were shown to be required for efforts to maintain the current status including vocational ethics, communication, collaboration, interpersonal relationship, self-control, emotional intelligence, and problemsolving. Unlike other studies, there were no items to restrict the input with excessive efforts due to low importance and high needs and to require the improvement efforts urgently due to high importance and low needs.

\section{Discussion}

Although there might be different under the environments of the nation and organization with the goals of prevention of dental diseases and enhancement of health, the roles of dental hygienists have been expanded not only as the clinicians but also investigators and managers ${ }^{10)}$. In particular, core competencies mean the required knowledge, skills, and attitude of the learners to solve the problems

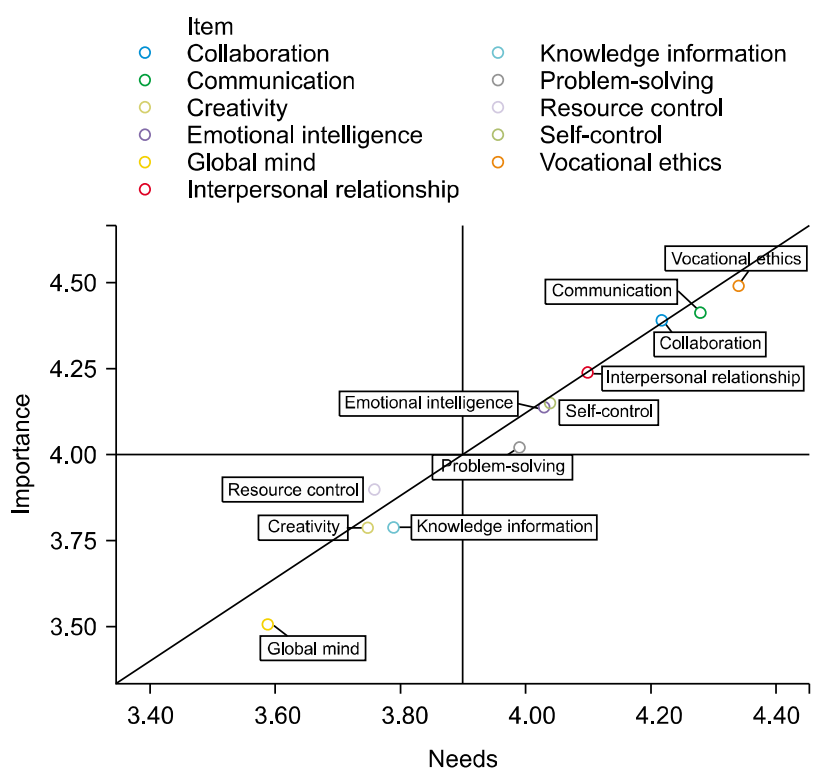

Fig. 2. Importance-Performance Analysis results by detailed item.

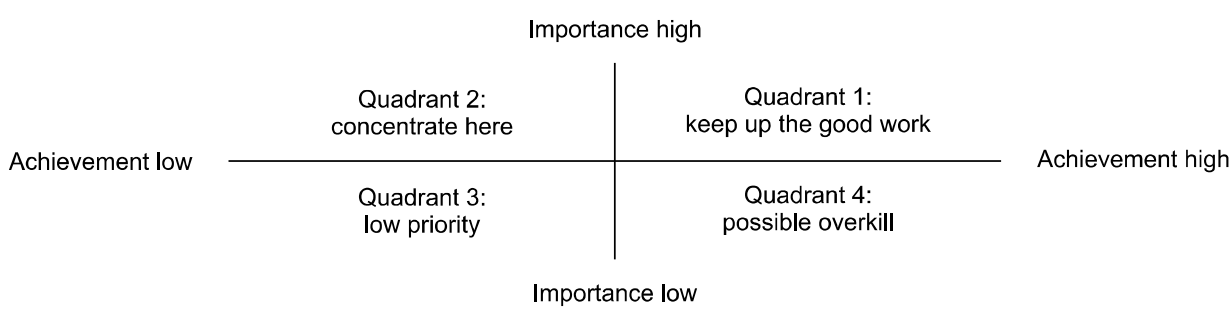

Fig. 1. Importance-Performance Analysis matrix. 
efficiently in multiple situations and they should be basic, common and integrative competencies that everyone can achieve by education rather than individuals' own unique ones $^{4}$. This study was aimed to provide the basic data to develop competent future dental hygienists by deducting the basic core competencies required for their job upon investigating the importance and needs on the basic core competencies in the subjects with dental hygienists who were working in the clinical practices. Upon the analysis results of importance and needs by areas on the basic core competencies among 11 competencies, both importance and needs were shown high in the orders of vocational ethics, communication, and collaboration with 4.49 and 4.34 points; 4.41 and 4.28 points; and 4.39 and 4.22 points, respectively. These results can be considered as the important basic core competencies to perform the required job of professional dental hygiene. Competencies required in the jobs these days are not only professional knowledge, skills, and attitude but also skills on the major and vocational basic capabilities to be able to solve a variety of problems flexibly in the clinical practices ${ }^{11)}$. For the sub-factors among 11 basic core competencies, 'creative attitude' and 'creative problem-solving' showed the highest importance and needs in the creativity, respectively, and 'problem-handling skill' showed the highest importance and needs in the problem-solving. This implicates that dental hygienists in the clinical practices should have the capabilities to understand the problem situations correctly to solve them and to handle them properly. Especially, organization members with enhanced competencies are considered to be able to approach multiple problems potentially to solve them as well as to think creatively upon participation in the changes actively ${ }^{12}$.

Lee et al. ${ }^{13)}$ reported that critical thinking style and problem-solving skill of dental hygienists affected their job performances directly. Above all, $44.1 \%$ of this study subjects were working in 'supporting clinical dentistry.' Various teaching and learning methods, such as problemsolving-centered participatory education programs (simulation, problem-centered, capstone design, and flipped learning classes) should be implemented so that the students can solve problems according to the complex medical environment.
'Collaborative communication' in collaboration, 'listening' in communication, 'conflict management' in interpersonal relationship, and 'emotion control' in emotional intelligence were shown the highest in importance and needs. Above all, in a dental medical environment that requires collaboration, I think it is an important competency in order to provide quality medical treatment only when communication about internal staff as well as cooperative communication about dental treatment occurs. In order to produce competent dental hygienists in the current situation of colleges where credits are decreasing in recent years, it is necessary to pay attention not only to the subject related to the job, but also to develop the basic core competencies to perform the job, and at the level of the Korean Dental Hygienist Association or academic society. During the refresher education, it is necessary to develop educational contents that can improve the communication skills suitable for the years of various personnel working in the dental medical field. With more specialized dental institutions, the skill sets required for dental hygienists have been widely expanded to preventive education, interpersonal relationship skills, management, and so on ${ }^{14)}$. This means dental hygienists as the middle managers and partners in the dental institutions ${ }^{15)}$ should develop communication skill to be able to develop harmonious interpersonal relationship so as to shorten the gap among different functions within the medical institutions and to cooperate with each other well ${ }^{16}$.

Ko and $\mathrm{Kim}^{17)}$ commented interpersonal relationship skill affected organizational cohesiveness, job satisfaction, and working efficiency by communication and interactions among organization members. Dental hygienists play roles to provide the patients with medical services and modulate peers and employees so as for them to concentrate on their patients upon direct contact with a variety of people and practices ${ }^{18)}$. Therefore, 'emotion control,' which is sub-factor of emotional intelligence among basic core competencies, should be clearly defined. as it is a sub-area that can appear when a dental hygienist performs a job. With respect to self-control and development among basic core competencies, 'self-recognition' in importance and 'selfassessment' and 'self-development' in needs were shown as the highest, and 'sense of responsibility' and 'ethical 
mind' in vocational ethics were shown high in needs as well as importance. Hospital environment should be supported for dental hygienists as the professional to provide the patients with high quality services, however, it is necessary for them to establish their own concept of dental professionals ${ }^{19)}$. This can be considered to affect job performances of dental hygienists positively when they acknowledge the importance of self-recognition and self-development. In addition, future education empathizes emotion and personality ${ }^{20)}$. Since the ethical mind of the professionals can be the basis of value determination in the job performances, it can be one of core competencies in the education. To perform the job of dental hygiene well in the medical institutions, it should be properly applied in the clinical practices in alignment with a variety of basic core competencies as well as professional knowledge. It is necessary to strengthen the competence of those in charge of guiding dental hygiene ethics in order to raise and establish ethical awareness of dental hygienists.

Lastly upon the analysis of difference between importance and needs using IPA matrix, 7 items among 11 competencies including vocational ethics, communication, collaboration, interpersonal relationship, self-control, emotional intelligence, and problem-solving showed high level in both importance and needs, reflecting the items to be necessary for the efforts to maintain the current status. These were repeated in those with higher scores in importance and needs among 11 competencies, which can be defined as the basic core competencies appropriate to perform dental hygienists' job. Also, 4 items including resource control and development, knowledge information utilization, creativity, and global mind showed lower priority, which reflects there were no items to restrict the input with excessive efforts due to low importance and high needs and to require the improvement efforts urgently due to high importance and low needs, unlike other studies.

The limitations of this study are difficulties in generalizing the results since this was conducted among the subjects of dental hygienists in some territories and in explaining the comparison results objectively because of lack of previous studies on the basic core competencies among dental hygienists. In addition, it is necessary to check the current level of basic core competencies through self competency evaluation at the current level of dental hygienists, and to further develop basic core competencies necessary for future dental hygienists.

However, this has the meaning to suggest the basic core competencies of dental hygienists required in the future society in alignment with their job. Further studies on the curricula should be conducted continuously to apply these basic core competencies.

\section{Notes}

\section{Conflict of interest}

No potential conflict of interest relevant to this article was reported.

\section{Ethical approval}

This study was approved by the Institutional Review Board of Dongnam Health University (IRB No. 1044371202003-HR-001-02).

\section{Author contributions}

Conceptualization: Sun-Mi Lee, Chun-Sun Lee, Myong-Suk Shin. Data acquisition: Myong-Suk Shin, Sun-Mi Lee, Chun-Sun Lee. Formal analysis: Sun-Mi Lee. Supervision: Chun-Sun Lee. Writing-original draft: Chun-Sun Lee, Myong-Suk Shin. Writing-review \& editing: Sun-Mi Lee, Myong-Suk Shin.

\section{ORCID}

Sun-Mi Lee, https://orcid.org/0000-0003-3133-8912

Chun-Sun Lee, https://orcid.org/0000-0001-7442-914X

Myong-Suk Shin, https://orcid.org/0000-0002-2820-4772

\section{References}

1. Hwang JO, Noh IK, Jung HY: An exploratory study on core competency of adult college students. J Core Competency Educ Res 1: 47-78, 2016.

2. Lee GH, Kwon HH, Lee JR, Lee SJ: The study on proper way for engineering university education: based on the perception of current competencies and expected competencies of engineering freshmen. J Eng Educ Res 13: 57-71, 2010. 
3. Kim DJ, Kim SY: Understanding and Issues on core competency and competency-based curriculum in higher education. J Core Competency Educ Res 2: 23-45, 2017.

4. Kim EJ, Seong MH: Educational needs of industry in core competencies and general education at universities - Focused on the health care industry. Korean J Gen Educ 11: 121-145, 2017.

5. Lee HW, Park SH, Lee SH: The educational needs analysis of core- competency training support program to improve the core-competency - in the case of Seoul National University. JCCER 4: 248-278, 2018

6. Baek PG: A study on the relationships and characteristics between Korean collegiate essential skills and undergraduates' individual variant factors. Korean J Gen Educ 7: 349-387, 2013.

7. Lee JI, Kim JH: A study on the relationship between college students' essential skills and academic achievement. J Vocat Educ Res 31: 227-246, 2012.

8. Kwon JG, Kim HS, Kim OJ, et al.: A study on the derivation of core competency for the training of professionals to the future industries. Council of NCS Base Center, pp.8-20, 2019.

9. Lee SH, Lee J: Importance-performance analysis for conceptions on 'good teaching' of physical education teachers in secondary school. J Korean Teach Educ 27: 317-341, 2010.

10. Yoon SU: Organizational culture, organizational structure and emotional labor of dental workers impact of convergence on job satisfaction. J Converg Inf Technol 10: 187-194. 2020. https://doi.org/10.22156/CS4SMB.2020.10.01.187

11. Park JH, Lee YH: Influence of dental hygienists' core competencies on job performance. J Dent Hyg Sci 17: 142-149, 2017. https://doi.org/10.17135/jdhs.2017.17.2.142

12. Laschinger HK, Havens DS: Staff nurse work empowerment and perceived control over nursing practice, conditions for work effectiveness. J Nurs Adm 26: 27-35, 1996. https://doi.org/10.1097/00005110-199609000-00007

13. Lee JE, Lee SY, Kim HJ: The effects of critical thinking disposition and problem solving ability on the work performance assessment of dental hygienists. J Dent Hyg Sci 17: 275-282, 2017. https://doi.org/10.17135/jdhs.2017.17.4.275

14. Kang BW: Analysis of psychological characteristics associated with organization commitment among clinical dental hygienists. Bulletin of Dongnam Health College 23: 19-28, 2005.

15. Park MY: A study on the satisfaction and stress factor of clinical practice for students in the department of dental hygiene. J Dent Hyg Sci 6: 243-249, 2006.

16. Lee SK, Hwang KS, Park YD, Beom KC: The relationship between factors influencing smooth communication among dental workers. J Korean Acad Oral Health 35: 85-92, 2011.

17. Ko HR, Kim JH: The relationships among emotional intelligence, interpersonal relationship, and job satisfaction of clinical nurses. J Korean Acad Soc Nurs Educ 20: 413-423, 2014.

https://doi.org/10.5977/jkasne.2014.20.3.413

18. Choi BK, Kim JS, Ha MN: Effects of emotional labor and job characteristics on job stress and turnover intention in dental hygienists using the structural equation model. J Korean Soc Dent Hyg 18: 31-42, 2018. https://doi.org/10.13065/jksdh.2018.18.01.31

19. Lee HS, Jang KA: Factors affecting clinical competence of dental hygienists. J Dent Hyg Sci 16: 331-338, 2016. https://doi.org/10.17135/jdhs.2016.16.5.331

20. Seo HJ, Lee JY: Analysis of future education trends using semantic network analysis. J Korean Assoc Educ Inf Media 24: 649-678, 2018. http://doi.org/10.15833/KAFEIAM.24.4.649 